Article

\title{
The Effect of Dietary Supplementation with Resveratrol on Growth Performance, Carcass and Meat Quality, Blood Lipid Levels and Ruminal Microbiota in Fattening Goats
}

\author{
Yujian Shen ${ }^{\dagger}$, Yuhang Jiang ${ }^{\dagger}$, Sanbao Zhang, Juhong Zou, Xiaotong Gao, Ying Song, Yu Zhang, Yan Hu, \\ Yanna Huang and Qinyang Jiang *
}

check for updates

Citation: Shen, Y.; Jiang, Y.; Zhang, S. Zou, J.; Gao, X.; Song, Y.; Zhang, Y.;

$\mathrm{Hu}$, Y.; Huang, Y.; Jiang, Q. The Effect of Dietary Supplementation with Resveratrol on Growth Performance,

Carcass and Meat Quality, Blood Lipid Levels and Ruminal Microbiota in Fattening Goats. Foods 2022, 11 598. https://doi.org/10.3390/ foods 11040598

Academic Editors:

Óscar López-Campos, Nuria Prieto Benavides and Jose Lorenzo Rodriguez

Received: 12 January 2022

Accepted: 16 February 2022

Published: 18 February 2022

Publisher's Note: MDPI stays neutral with regard to jurisdictional claims in published maps and institutional affiliations.

Copyright: (C) 2022 by the authors. Licensee MDPI, Basel, Switzerland. This article is an open access article distributed under the terms and conditions of the Creative Commons Attribution (CC BY) license (https:// creativecommons.org/licenses/by/ $4.0 /$ )
College of Animal Science and Technology, Guangxi University, 100 East University Road, Nanning 530004, China; shenyj1991@126.com (Y.S.); jiangyh1996@126.com (Y.J.); gxuzsb@126.com (S.Z.); zz898600@126.com (J.Z.); gaoxt855@163.com (X.G.); sy970526@126.com (Y.S.); zy13679430243@126.com (Y.Z.); hy2789307025@163.com (Y.H.); huangyn@gxu.edu.cn (Y.H.)

* Correspondence: jiangqinyang2013@gxu.edu.cn

† These authors contributed equally to this work.

\begin{abstract}
This study investigated the effects of resveratrol (RES) supplementation on the growth performance, carcass and meat quality, blood lipid levels and ruminal bacterial microbiota of fattening goats. A total of forty castrated Nubian goats $(28.25 \pm 0.26 \mathrm{~kg}$ body weight) were randomly divided into four groups and provided with diets containing different levels of RES (0, 150, 300 and 600 $\mathrm{mg} / \mathrm{kg}$ ) for $120 \mathrm{~d}$. The results showed that RES increased redness and intramuscular fat content, whilst reducing shear force in the longissimus dorsi muscle of goats $(p<0.05)$. In addition, the final weight, average daily gain, hot carcass weight, net meat weight, carcass lean percentage and eye muscle area of goats were significantly increased in the $150 \mathrm{mg} / \mathrm{kg}$ RES group compared with the other three groups, while those in the $600 \mathrm{mg} / \mathrm{kg}$ RES group significantly decreased $(p<0.05)$. RES significantly decreased serum triacylglycerol and LDL-C contents $(p<0.05)$, and increased HDL-C content and the HDL-C/TC ratio $(p<0.05)$. Supplementation with $150 \mathrm{mg} / \mathrm{kg}$ RES also increased the proportion of Acetitomaculum and Moryella, genera comprising short-chain fatty acid-producing bacteria. The present study indicated that an appropriate supplemental level of RES could improve the growth performance, neat percentage, meat quality, ruminal microbiota and serum lipid levels of fattening goats.
\end{abstract}

Keywords: resveratrol; goat; growth performance; meat quality; ruminal microbiota

\section{Introduction}

Resveratrol (RES) is a variety of non-flavonoid polyphenol with a stilbene structure, which mainly occurs in grape, peanut, mulberry and polygonum cuspidatum [1]. It is reported that RES has a wide range of biological activities, including antioxidant activity [2], antiinflammatory activity [3] and a regulatory role in energy metabolism [4]. Therefore, RES has the potential to be an effective dietary supplement to regulate body metabolism.

Recently, more and more scholars have performed numerous studies on the effects of RES supplementation in livestock and poultry production. In poultry, dietary RES supplementation has been shown to improve the quality of pork by changing the muscle fiber characteristics and antioxidant capacity [5,6]. Moreover, RES has been shown to act as an antioxidant to reduce the degradation in meat quality observed in broilers subjected to transport and heat stresses [7,8]. Maternal dietary RES has been found to increase average daily weight gain in piglets [9]. However, the effects of dietary RES supplementation on the growth performance and meat quality of fattening goats have not been reported.

Although RES has a variety of biological activities, its low bioavailability is in contrast to its biological function [10-12]. Azorín-Ortuño et al. (2011) found that only 0.5\% of RES 
and its metabolites remained in the tissues and organs of pigs, and up to $65.1 \%$ of RES and its metabolites remained in the gastrointestinal tract after $6 \mathrm{~h}$ following feeding with RES (5.9 mg/kg BW) [13]. Dietary RES supplementation has been shown to significantly affect the growth of gut microbiota, increase the abundance of beneficial bacteria in rats [14] and to ameliorate obesity and liver steatosis through regulation of gut microbiota composition [11,15]. In ruminants, the rumen is one of the most important of all the gastrointestinal organs for digestion, metabolism and nutrition absorption, where feed components can be degraded, transformed and utilized by ruminal microbiota [16,17]. Therefore, it is of great significance to clarify the effects of dietary RES on rumen fermentation and rumen microbiota. However, previous studies on RES in ruminants mainly focus on its impact on methane emissions [18,19], whilst the effects of dietary RES supplementation on the rumen microbiota of fattening goats have not been reported.

This experiment was conducted to study the effects of different levels of RES on carcass traits, meat quality traits, serum lipid metabolism levels and ruminal microbial diversity in goats to clarify the application potential of RES in goat production.

\section{Material and Methods}

\subsection{Animals and Experimental Diets}

All experiments were approved by the Institutional Animal Care and Welfare Committee of Guangxi University (Nanning, China). A total of 40 (180 \pm 3 d old) healthy castrated male Nubian goats with an average initial body weight of $28.25 \mathrm{~kg}$ were randomly divided into four groups with 10 duplicates in every group. Each goat was housed in a pen with a size of $3.0 \mathrm{~m} \times 1.5 \mathrm{~m}$. The goat houses were cleaned and disinfected regularly to keep the paddock ventilated, sanitary and dry. The groups were stochastically allotted to each of four dietary treatments including a control diet (basal diet) and RES containing diets (150, 300 or $600 \mathrm{mg} / \mathrm{kg}$ RES + basal diet). Ingredient compositions and nutrient contents of the basal diets for goats are presented in Table 1. The RES used in the research was purchased from Wan Fang Biotechnology CO., Ltd. (Xi'an, China) and had a purity of 98.9\%. We first mixed RES into corn starch to achieve the required proportions for each diet. The goats were then fed with the corresponding RES-supplemented feed at 7:00 every morning. Goats were free to eat basal diets from 7:30 to 19:30 every day. Goats also had free access to water and a salt block during the trial period. The feeding experiment lasted for $120 \mathrm{~d}$, and the daily feed intake of each goat was recorded to calculate average daily feed intake (ADFI). Individual body weight was determined before and after the trial to calculate the average daily gain (ADG) and feed conversion ratio (FCR). FCR was calculated as the ratio of total feed intake to total weight gain over the entire trial period.

Table 1. Dietary ingredients and nutrient content of basal diets in fattening goats.

\begin{tabular}{cccc}
\hline Ingredients, $\%$ & Content & Nutrition Levels, $\%$ & Content \\
\hline Corn & 16.30 & Crude protein & 17.00 \\
Palm Kernel Expeller & 21.00 & Neutral detergent fiber & 43.52 \\
Peanut vine & 12.00 & Crude fat & 2.72 \\
Soybean meal & 3.00 & Calcium,Ca & 0.65 \\
Molasses & 2.00 & Total Phosphorus,TP & 0.43 \\
Manioc waste & 12.00 & Crude ash & 5.76 \\
Bagasse & 6.00 & Nitrogen free exteact & 22.65 \\
Corn skin & 4.00 & Acid detergent fiber & \\
Cassava alcohol residue & 9.00 & & \\
rice mill by-product & 5.00 & & \\
Urea & 1.20 & & \\
Dicalcium phosphate & 0.40 & & \\
Limestone & 1.00 & & \\
Bentonite & 4.00 & & \\
Rumen protected fat & 1.00 & & \\
Premix feed & 2.10 & & \\
Total & 100.00 & & \\
\hline
\end{tabular}




\subsection{Slaughter Surveys and Sampling}

At the end of the trial, the goats were fasted for $24 \mathrm{~h}$. Before slaughtering, blood samples were collected from the jugular veins of each goat using empty collection tubes. The serum samples (supernatant) were collected immediately after the blood samples had been centrifuged at $3000 \times g$ for $15 \mathrm{~min}$ at $4{ }^{\circ} \mathrm{C}$ and were then stored at $-80{ }^{\circ} \mathrm{C}$ for hematological analysis.

Six goats from each group were randomly selected for slaughter, which was conducted in the large animal slaughtering room of the animal science teaching experimental base of Guangxi University. All goats were slaughtered in accordance with the agricultural industry standard of the People's Republic of China (NY/T3469-2019). Twenty-four goats were stunned, bled, skinned, gutted and then split along the midline. Hot carcass weight and net meat weight were recorded, then used to calculate dressing percentage and neat percentage. The dressing percentage refers to the percentage of carcass weight to pre-slaughter body weight, which is calculated as dressing percentage $(\%)=$ (hot carcass weight/pre-slaughter body weight $) \times 100$. The net meat percentage refers to net meat weight as a percentage of hot carcass weight, i.e., $(\%)=($ net meat weight $/$ hot carcass weight $) \times 100$. The longissimus dorsi (LD) area between the 12th and 13th rib was measured using a square $\mathrm{cm}\left(\mathrm{cm}^{2}\right)$ grid.

Rumen fluid samples were collected from the rumen of each goat immediately after slaughter. The rumen contents were filtered through four layers of cheesecloth and collected into cryopreservation tubes, which were immediately frozen in liquid nitrogen and then stored at $-80^{\circ} \mathrm{C}$ for subsequent analysis.

\subsection{Meat Quality and Blood Chemical Analysis}

The meat quality of 24 goats was tested and analyzed according to the agricultural industry standard of the People's Republic of China (NY/T1333-2007). A sample of LD muscle from the same area of each carcass was collected to determine $\mathrm{pH}$ value, color, conductivity, shear force and intramuscular fat (IMF) content.

The $\mathrm{pH}$ value in the LD muscle was determined at $45 \mathrm{~min}$ and $24 \mathrm{~h}$ postmortem using a pH meter (pH-STAR, Matthäus GmbH \& Co. KG, Germany) equipped with a temperature compensation and calibrated using two buffers $(\mathrm{pH} 4.64$ and 7.0). The meat color was detected at $45 \mathrm{~min}$ postmortem using a colorimeter (OPTO-Star, Matthäus GmbH \& Co. KG, Germany) based on the specific parameters: $L^{*}$ (lightness), $a^{*}$ (redness) and $b^{*}$ (yellowness). The colorimeter was calibrated using a white tile before measurements were taken. After removing other connective tissue, the surface of the LD muscle was exposed to air for 20 min of blooming, and then measured for meat color. The conductivity of the LD muscle samples was measured using a carcass conductivity meter (LF-Star, Matthäus GmbH \& Co. KG, Eckelsheim, Germany). The instrument was calibrated before measurements were taken. The probe was inserted into the sample, following the muscle fiber direction, and the conductivity values were recorded after a stabilization period. The $\mathrm{pH}$, meat color and conductivity were measured repeatedly a total of 6 times, and the average values were used for further data analysis. Warner-Bratzler shear force (WBSF) was measured using a Shear Force Instrument (Mecmesin Ltd., West Sussex, UK). Briefly, the LD samples were placed in a water bath at $80^{\circ} \mathrm{C}$. After the central temperature reached $70{ }^{\circ} \mathrm{C}$, the samples were removed and cooled to room temperature. Six cylindrical cores with a diameter of $1.27 \mathrm{~cm}$ were taken from each sample parallel to the direction of the muscle fibers to measure the shear force. The IMF content of the LD muscle was determined using the Soxhlet extraction method with petroleum ether extraction according to AOAC (1995) methods [20], and the results were expressed as percentages of the weight of wet muscle.

Concentrations of triglycerides (TG), total cholesterol (TC), low-density lipoprotein (LDL-C) and high-density lipoprotein (HDL-C) of serum samples were determined using automatic biochemical analyzer and direct enzymatic kits (Shanghai Kehua Bio-engineering Co., Ltd., Shanghai, China) according to the manufacturer's instructions. Blood physiological indexes were measured using an automatic animal blood cell analyzer (Prokan Electronics Inc., Shenzhen, China). 


\subsection{Microbiota Analysis by $16 S$ Sequencing}

The genomic DNA was extracted from each goat's rumen fluid sample (approx. $20 \mathrm{~g}$ ) using a PowerSoil@DNA Isolation Kit (MO BIO Laboratories, Inc., Carlsbad, CA, USA) according to the manufacturer's protocol. The concentration and purity of genomic DNA were measured using a NanoDrop 2000 instrument (Thermo Fisher Scientific, Dreieich, Germany), and the quality was evaluated via agarose gel electrophoresis analysis. The full-length bacterial 16S rRNA genes were amplified using rumen fluid genomic DNA as a template. The primers for PCR amplification were universal primers $27 \mathrm{~F}\left(5^{\prime}-\right.$ AGRGTTTGATYNTGGCTCAG-3') and 1492R (5'-TASGGHTACCTTGTTASGACTT-3') labeled with $16 \mathrm{nt}$ barcodes. PCR reactions were conducted using a $30 \mu \mathrm{L}$ reaction including $1.5 \mu \mathrm{L}$ of extracted genomic DNA, $3 \mu \mathrm{L}$ of each primer $(10 \mu \mathrm{M}), 5 \mu \mathrm{L}$ of KOD OneTM PCR Master Mix (Toyobo Co., Ltd., Osaka, Japan) and $10.5 \mu \mathrm{L}$ of nuclease-free Water. The thermocycling program was as follows: an initial denaturation at $95{ }^{\circ} \mathrm{C}$ for $2 \mathrm{~min}$; followed by 25 cycles of $98^{\circ} \mathrm{C}$ for $10 \mathrm{~s}$ before annealing at $55^{\circ} \mathrm{C}$ for $30 \mathrm{~s}$ and at $72{ }^{\circ} \mathrm{C}$ for $1.5 \mathrm{~min}$; and a final extension at $72{ }^{\circ} \mathrm{C}$ for $2 \mathrm{~min}$. PCR results were verified using $1.8 \%$ agarose gel electrophoresis, subsequently purified using the PureLink PCR Purification Kit (Thermo Fisher Scientific, Waltham, MA, USA) and then quantified using a Qubit 2.0 Fluorometer (Thermo Fisher Scientific, Waltham, MA, USA). The amplicon sequencing libraries were built and quality controlled. Then, qualified libraries were sequenced on PacBio Sequel II platform (Pacific Biosciences of California, Inc., Menlo Park, CA, USA).

The bioinformatics analysis of this study was carried out with the help of Biomarker Technologies Corporation, Beijing, China. The circular consensus sequencing (CCS) reads obtained from the raw reads were distributed to the matching samples on the basis of their barcodes using the LIMA software (version 1.7.0). Then, the CCS reads without primers and outside of the length range (1200-1650 bp) were removed using the Cutadapt software (version 2.7). The chimeric sequences were identified and removed to obtain the sequences of effective CCS using the UCHIME software (V4.2). USEARCH software (V10.0) was used to cluster reads with a $97 \%$ similarity cutoff to obtain the operational taxonomic unit (OTU), and the OTU was filtered when RE abundance was less than $0.005 \%$. The RDP Classifier (version 2.2) was used to sort the feature sequences into different taxonomic groups based on the SILVA 132 reference, with a confidence threshold of $80 \%$.

\subsection{Statistical Analysis}

Data were presented as the mean \pm standard error (SEM) and statistically analyzed using a one-way analysis of variance (ANOVA) and least significant difference (LSD) test using SPSS 22.0. Statistical difference was considered significant or extremely significant at $p<0.05$ or $p<0.01$.

Diversity analyses of 24 samples were calculated and displayed using the QIIME (V1.8.0) and R software (V3.2.0), respectively. The measurement indexes of $\alpha$ diversity analyses, including Chao1, Ace, Shannon, Simpson and Coverage, were assessed using mothur (version 1.30.1). Chao1 and Ace indexes are used to measure species richness, while Shannon and Simpson indexes measure species diversity. Beta diversity analysis was computed using the Bray-Curtis distance matrix to calculate the distance between samples, and Principal coordinates analysis (PCoA) plots were used to evaluate the variation among different groups.

Characteristic differences among different treatments were analyzed using the linear discriminant analysis effect size (LEfSe). The LEfSe analysis was conducted using non-parametric factorial Kruskal-Wallis and Wilcoxon rank sum-rank tests with a linear discriminant analysis (LDA) score $>3$ and $p<0.05$. The function prediction of the ruminal microbiota was performed using phylogenetic investigation of community by reconstruction of unobserved States 2 (PICRUSt2). 


\section{Results}

\subsection{Growth and Carcass Characteristics}

As shown in Table 2, compared with the control group, the final weight and ADG were significantly increased $(p<0.05)$ in the $150 \mathrm{mg} / \mathrm{kg}$ RES group and observably decreased $(p<0.05)$ in the $600 \mathrm{mg} / \mathrm{kg}$ RES group. Furthermore, the $600 \mathrm{mg} / \mathrm{kg}$ RES group had lower ADFI $(p<0.05)$ and higher FCR $(p<0.05)$ than the other three groups. Dietary $300 \mathrm{mg} / \mathrm{kg}$ RES supplementation had no significant effect on the growth performance of goats.

Table 2. Effect of dietary supplementation with resveratrol on growth performance and carcass characteristics of fattening goats.

\begin{tabular}{|c|c|c|c|c|}
\hline Item & Control & $150 \mathrm{mg} / \mathrm{kg}$ & $300 \mathrm{mg} / \mathrm{kg}$ & $600 \mathrm{mg} / \mathrm{kg}$ \\
\hline Final body weight (kg) & $45.09 \pm 0.63^{b}$ & $48.90 \pm 1.01^{\mathrm{a}}$ & $44.67 \pm 0.47^{b}$ & $38.04 \pm 0.76^{c}$ \\
\hline Initial body weight (kg) & $28.32 \pm 0.50$ & $28.43 \pm 0.49$ & $28.05 \pm 0.45$ & $28.20 \pm 0.68$ \\
\hline $\operatorname{ADG}(\mathrm{g} / \mathrm{d})$ & $139.75 \pm 4.08^{b}$ & $170.59 \pm 5.24^{\mathrm{a}}$ & $138.44 \pm 4.10^{b}$ & $82.06 \pm 4.86^{c}$ \\
\hline ADFI (kg/d) & $1.10 \pm 0.09^{\mathrm{a}}$ & $1.17 \pm 0.11^{\mathrm{a}}$ & $1.11 \pm 0.14^{\mathrm{a}}$ & $0.89 \pm 0.07^{b}$ \\
\hline FCR (kg/kg) & $7.87 \pm 0.33^{b}$ & $6.99 \pm 0.71^{b}$ & $7.48 \pm 0.45^{b}$ & $9.20 \pm 0.37^{\mathrm{a}}$ \\
\hline Hot carcass weight $(\mathrm{kg})$ & $20.24 \pm 0.43^{b}$ & $22.72 \pm 1.00^{\mathrm{a}}$ & $20.46 \pm 0.53^{b}$ & $17.69 \pm 0.51^{c}$ \\
\hline Net meat weight $(\mathrm{kg})$ & $7.44 \pm 0.13^{b}$ & $8.62 \pm 0.41^{\mathrm{a}}$ & $7.32 \pm 0.11^{b}$ & $5.71 \pm 0.24^{c}$ \\
\hline Dressing percentage (\%) & $45.32 \pm 0.98$ & $45.77 \pm 0.93$ & $45.11 \pm 1.36$ & $46.50 \pm 1.15$ \\
\hline Neat percentage (\%) & $36.38 \pm 0.43^{b}$ & $37.91 \pm 0.45 \mathrm{a}$ & $36.21 \pm 0.32^{b}$ & $34.20 \pm 0.72^{c}$ \\
\hline LA $\left(\mathrm{cm}^{2}\right)$ & $13.33 \pm 0.36^{b}$ & $15.21 \pm 0.34^{\mathrm{a}}$ & $13.83 \pm 0.37^{\mathrm{b}}$ & $11.83 \pm 0.54^{c}$ \\
\hline
\end{tabular}

ADG—average daily gain; ADFI-average daily feed intake; FCR—feed conversion ratio; LA-longissimus dorsi area. Values are shown as mean \pm SEM. For the first five indexes, $n=10$; for the last five indexes, $n=6$. Values within a row followed by different lowercase letters are significantly different $(p<0.05)$. Dressing percentage $(\%)$ $=($ hot carcass weight $/$ pre-slaughter body weight $) \times 100$; Net meat percentage $(\%)=$ (net meat weight $/$ hot carcass weight) $\times 100$.

Interestingly, dietary supplementation with $150 \mathrm{mg} / \mathrm{kg}$ RES resulted in greater hot carcass weight, net meat weight, carcass neat percentage and enlarged LD muscle area than were observed for the other supplemental levels $(p<0.05)$, while supplementation with $600 \mathrm{mg} / \mathrm{kg}$ RES had the opposite effect (Table 2). There was no significant difference in growth performance and carcass characteristics between the control and $300 \mathrm{mg} / \mathrm{kg}$ RES group. There was no noteworthy difference in dressing percentage among the four groups.

\subsection{Meat Quality Characteristics}

Dietary RES supplementation increased the $\mathrm{a}^{*}$ value and IMF content and reduced the shear force in the LD muscle of goats compared with the control group $(p<0.05)$. No differences in these three indexes $(p>0.05)$ were observed among the $150 \mathrm{mg} / \mathrm{kg}, 300 \mathrm{mg} / \mathrm{kg}$ and $600 \mathrm{mg} / \mathrm{kg}$ RES group (Table 3). There was no significant difference in other meat quality indexes $\left(\mathrm{pH}_{45 \mathrm{~min}}\right.$ $\mathrm{pH}_{24 h}, \mathrm{~L}^{*}, \mathrm{~b}^{*}$ and conductivity) among the four groups ( $\left.p>0.05\right)$.

Table 3. Effect of dietary supplementation with resveratrol on meat quality of fattening goats.

\begin{tabular}{ccccc}
\hline Item & Control & $\mathbf{1 5 0} \mathbf{~} \mathbf{g} / \mathbf{k g}$ & $\mathbf{3 0 0} \mathbf{~} \mathbf{g} / \mathbf{k g}$ & $\mathbf{6 0 0 ~} \mathbf{~ g} / \mathbf{k g}$ \\
\hline $\mathrm{pH}_{45 \mathrm{~min}}$ & $6.46 \pm 0.18$ & $6.49 \pm 0.07$ & $6.46 \pm 0.08$ & $6.70 \pm 0.07$ \\
$\mathrm{pH}_{24 \mathrm{~h}}$ & $6.00 \pm 0.06$ & $5.80 \pm 0.06$ & $5.96 \pm 0.17$ & $5.86 \pm 0.15$ \\
conductivity & $3.04 \pm 0.07$ & $3.28 \pm 0.11$ & $3.04 \pm 0.06$ & $3.17 \pm 0.06$ \\
Meat color: & & & \\
$\mathrm{L}^{*}$ & $33.42 \pm 0.43$ & $33.00 \pm 0.74$ & $32.30 \pm 0.85$ & $32.80 \pm 0.52$ \\
$\mathrm{a}^{*}$ & $7.32 \pm 0.22^{\mathrm{b}}$ & $8.40 \pm 0.27^{\mathrm{a}}$ & $9.39 \pm 0.49^{\mathrm{a}}$ & $8.92 \pm 0.28^{\mathrm{a}}$ \\
$\mathrm{b}^{*}$ & $6.20 \pm 0.21$ & $6.66 \pm 0.46$ & $6.60 \pm 0.35$ & $6.75 \pm 0.19$ \\
Shear force(N) & $86.00 \pm 4.10^{\mathrm{a}}$ & $70.16 \pm 2.55^{\mathrm{b}}$ & $66.50 \pm 2.01^{\mathrm{b}}$ & $63.23 \pm 3.41^{\mathrm{b}}$ \\
$\mathrm{IMF}(\%)$ & $2.49 \pm 0.10^{\mathrm{b}}$ & $3.31 \pm 0.34^{\mathrm{a}}$ & $3.48 \pm 0.17^{\mathrm{a}}$ & $4.13 \pm 0.46^{\mathrm{a}}$ \\
\hline
\end{tabular}

$\mathrm{L}^{*}$ - brightness of color; $\mathrm{a}^{*}$-redness; $\mathrm{b}^{*}$-yellowness; IMF-intramuscular fat content, $n=6$. Values are shown as mean \pm SEM, $n=6$. Values within a row followed by different lowercase letters are significantly different $(p<0.05)$. 


\subsection{Blood Physiological and Biochemical Indexes}

RES had no effect on serum TC content $(p>0.05)$ but resulted in lower $(p<0.05)$ TG and LDL-C contents, and a greater $(p<0.05)$ HDL-C content and HDL-C/TC ratio (Table 4$)$. In addition, there was no remarkable difference in blood physiological indexes among the four groups of finishing goats ( $p>0.05$; Table S1).

Table 4. Effect of dietary supplementation with resveratrol on blood parameters of fattening goats.

\begin{tabular}{ccccc}
\hline Item & Control & $\mathbf{1 5 0} \mathbf{~} \mathbf{g} / \mathbf{k g}$ & $\mathbf{3 0 0} \mathbf{~} \mathbf{g} / \mathbf{k g}$ & $\mathbf{6 0 0 ~} \mathbf{~ g} / \mathbf{k g}$ \\
\hline TG (mmol/l) & $0.31 \pm 0.01^{\mathrm{a}}$ & $0.27 \pm 0.01^{\mathrm{b}}$ & $0.26 \pm 0.02^{\mathrm{b}}$ & $0.20 \pm 0.02^{\mathrm{c}}$ \\
TC (mmol/l) & $2.55 \pm 0.14$ & $2.52 \pm 0.14$ & $2.58 \pm 0.13$ & $2.50 \pm 0.09$ \\
HDL-C (mmol/l) & $0.96 \pm 0.06^{\mathrm{b}}$ & $1.36 \pm 0.08^{\mathrm{a}}$ & $1.49 \pm 0.11^{\mathrm{a}}$ & $1.45 \pm 0.09^{\mathrm{a}}$ \\
LDL-C (mmol/l) & $0.63 \pm 0.13^{\mathrm{a}}$ & $0.21 \pm 0.08^{\mathrm{b}}$ & $0.22 \pm 0.07^{\mathrm{b}}$ & $0.25 \pm 0.06^{\mathrm{b}}$ \\
HDL-C/TC (\%) & $38.33 \pm 4.00^{\mathrm{b}}$ & $54.29 \pm 3.34^{\mathrm{a}}$ & $57.89 \pm 3.38^{\mathrm{a}}$ & $58.28 \pm 3.51^{\mathrm{a}}$ \\
\hline
\end{tabular}

TG—-triacylglycerol; TC—-total cholesterol; HDL-C—high-density lipoprotein cholesterol; LDL-C-low-density lipoprotein cholesterol. Values are shown as mean \pm SEM, $n=6$. Values within a row followed by different lowercase letters are significantly different $(p<0.05)$.

\subsection{Effects of Dietary RES Supplementation on Rumen Bacterial Microbiota}

3.4.1. Taxonomic Identification of Rumen Bacteria across Treatments

To study the effects of dietary RES supplementation on rumen fermentation and rumen microbiota, full-length $16 \mathrm{~S}$ rRNA sequencing was used. This sequencing produced a total of 185,712 raw CCS sequences (range $=6174$ to 8031 , SEM $=95$ ), obtained from 24 samples using the PacBio platform (Table S2). After read-quality filtering, a total of 165,586 high-quality effective CCS sequences were acquired, with $6629 \pm 274,6980 \pm 75,6830 \pm 177$ and $7159 \pm 33$ sequences in the control, $150 \mathrm{mg} / \mathrm{kg}$ RES, $300 \mathrm{mg} / \mathrm{kg}$ RES and $600 \mathrm{mg} / \mathrm{kg}$ RES group, respectively (Table S2). Based on a $97 \%$ sequence similarity, the average number of OTUs among all samples was 195 (range $=77$ to $293, \mathrm{SEM}=11$ ). The rarefaction curves on the number of OTUs showed that the sequencing depth in this study was sufficient to characterize the bacterial microbiota of the rumen fluid samples (Figure S1).

As shown in Figure 1A, a group of 305 OTUs was shared among all four groups. The numbers of OTUs exclusive to the ruminal liquid of the goats in the control, $150 \mathrm{mg} / \mathrm{kg}$ RES, $300 \mathrm{mg} / \mathrm{kg}$ RES, and $600 \mathrm{mg} / \mathrm{kg}$ RES group were 5, 1, 11, 10, respectively, indicating that the four treatment groups had different rumen microbial species. A total of 14 phyla, 19 classes, 25 orders, 39 families, 120 genera and 144 species were detected across all the rumen fluid samples. The top 10 phyla, genera and species in terms of relative abundance among the ruminal bacteria are shown in Figure 1B-D.

\subsubsection{Effects of Dietary RES Supplementation on Microbial Diversity of Rumen Bacteria}

The microbiota diversity values of the four groups exhibited no apparent differences according to $\alpha$ diversity indexes (ACE, Chao1, Shannon and Simpson) and the PCoA analysis based on both unweighted and weighted Unifrac distances (Figure 2), except that the $600 \mathrm{mg} / \mathrm{kg}$ RES group exhibited a higher Chao1 diversity index than the $150 \mathrm{mg} / \mathrm{kg}$ RES group ( $p<0.05$; Table 5 ), and some changes in the composition of the bacterial community, largely at the genus (Figure S2A) and species (Figure S2B) levels, between different groups. 
A

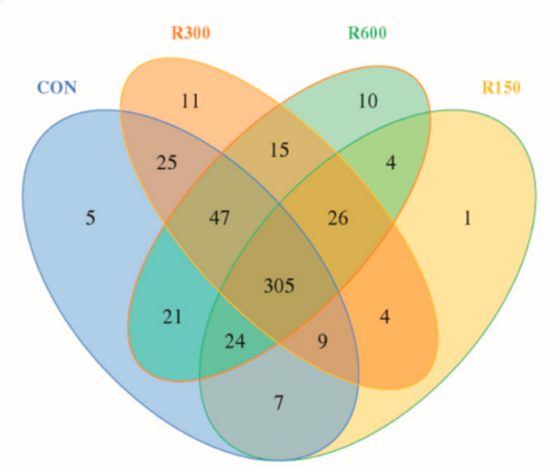

C

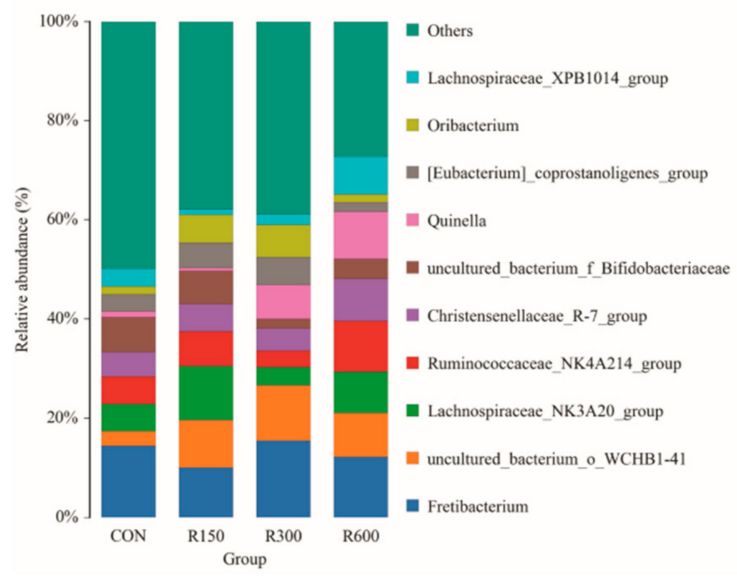

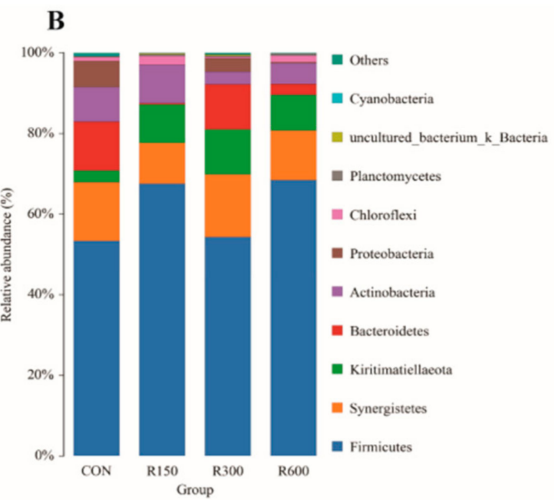

D

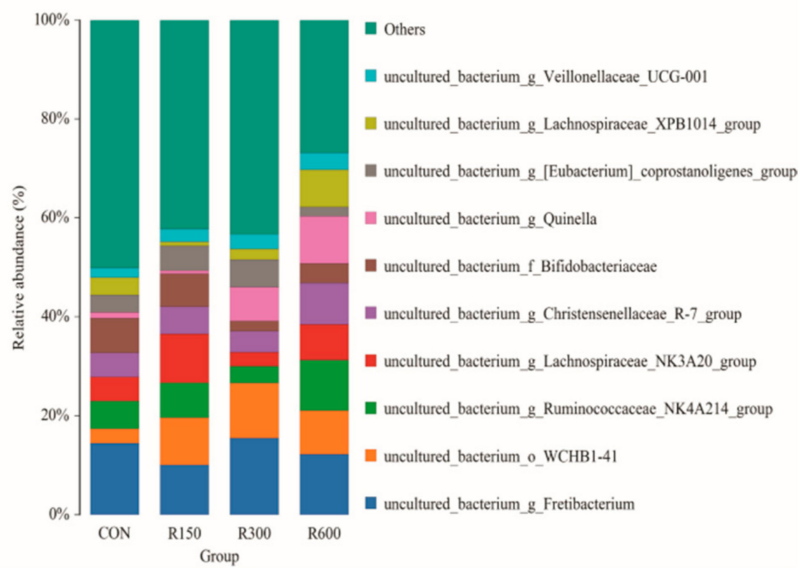

Figure 1. Effect of dietary supplementation with resveratrol on ruminal microbiota composition of fattening goats. (A) Operational taxonomic unit (OUT) Venn diagram. The number within each differently colored overlapping area is the number of OTUs shared by the overlapping groups. Nonoverlapping areas indicate the number of OTUs unique to each group. The top 10 phyla (B), genera (C) and species (D) of the ruminal bacteria across treatments. CON, the control group; R150, the $150 \mathrm{mg} / \mathrm{kg}$ RES group; R300, the $300 \mathrm{mg} / \mathrm{kg}$ RES group; R600, the $600 \mathrm{mg} / \mathrm{kg}$ RES group.
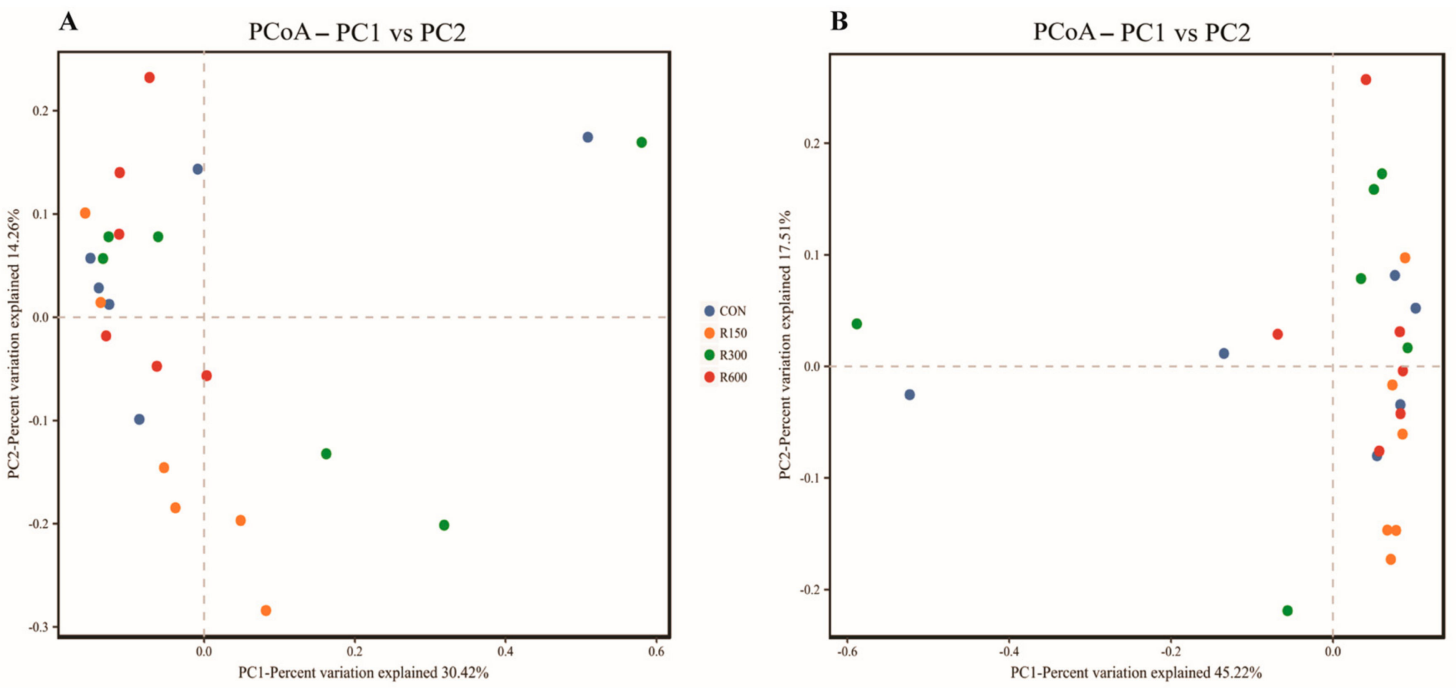

Figure 2. Effect of dietary supplementation with resveratrol on bacterial community structure (Principal coordinate analysis (PCoA)) in rumen fluid samples of fattening goats. PCoA based on unweighted (A) and weighted (B) Unifrac matrices. 
Table 5. Effect of dietary supplementation with resveratrol on bacterial alpha diversity indexes in rumen fluid samples of fattening goats.

\begin{tabular}{|c|c|c|c|c|}
\hline Item & Control & $150 \mathrm{mg} / \mathrm{kg}$ & $300 \mathrm{mg} / \mathrm{kg}$ & $600 \mathrm{mg} / \mathrm{kg}$ \\
\hline Chao1 & $263.31 \pm 38.20^{a b}$ & $230.17 \pm 12.65^{b}$ & $218.45 \pm 40.32^{a b}$ & $280.51 \pm 15.24^{\mathrm{a}}$ \\
\hline ACE & $249.24 \pm 27.79$ & $228.30 \pm 14.09$ & $209.50 \pm 40.54$ & $274.90 \pm 16.12$ \\
\hline Shannon & $5.08 \pm 0.41$ & $5.27 \pm 0.19$ & $4.84 \pm 0.39$ & $5.25 \pm 0.37$ \\
\hline Simpson & $0.92 \pm 0.023$ & $0.93 \pm 0.020$ & $0.92 \pm 0.019$ & $0.92 \pm 0.011$ \\
\hline
\end{tabular}

Values are shown as mean \pm SEM, $n=6$. Values within a row followed by different lowercase letters are significantly different $(p<0.05)$.

\subsubsection{Differential Rumen Bacterial Taxa among Different Treatments}

We made pairwise comparisons of the relative abundances of specific microbes across the four groups. At the phylum level (Figure 3A-E), the $600 \mathrm{mg} / \mathrm{kg}$ RES group showed a higher relative abundance of Kiritimatiellaeota than the control group $(p<0.05)$. Compared with the $150 \mathrm{mg} / \mathrm{kg}$ RES group, the $300 \mathrm{mg} / \mathrm{kg}$ RES group had higher abundance of Bacteroidetes and lower abundance of Actinobacteria and Chloroflexi $(p<0.05)$. The relative abundance of Proteobacteria in the $600 \mathrm{mg} / \mathrm{kg}$ RES group was significantly higher than that in the $150 \mathrm{mg} / \mathrm{kg}$ RES group $(p<0.05)$. There were 23 bacterial genera significantly affected by RES supplemental levels (Table S3). Importantly, obviously higher levels of Acetitomaculum (Figure 3F) and Moryella (Figure 3G) were observed in the ruminal microbiota of the $150 \mathrm{mg} / \mathrm{kg}$ RES group than in the other three groups $(p<0.05)$. In addition, the $600 \mathrm{mg} / \mathrm{kg}$ RES group had a significantly higher relative abundance of Desulfobulbus than the other three groups ( $p<0.05$, Figure $3 \mathrm{H})$. A total of 26 bacterial species showed significantly higher or lower relative abundance in the pairwise comparisons, mostly corresponding to the genus level (Table S4).

A
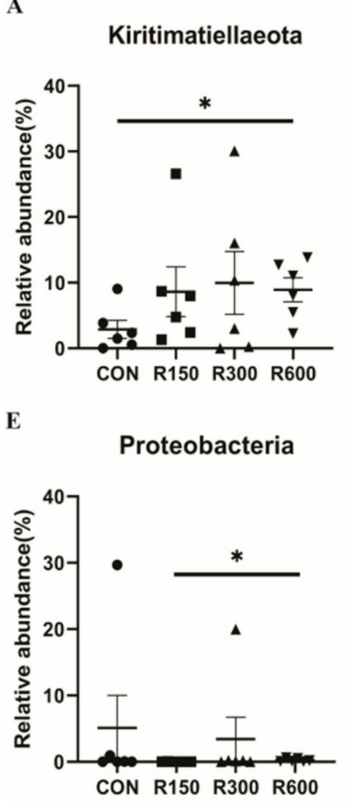
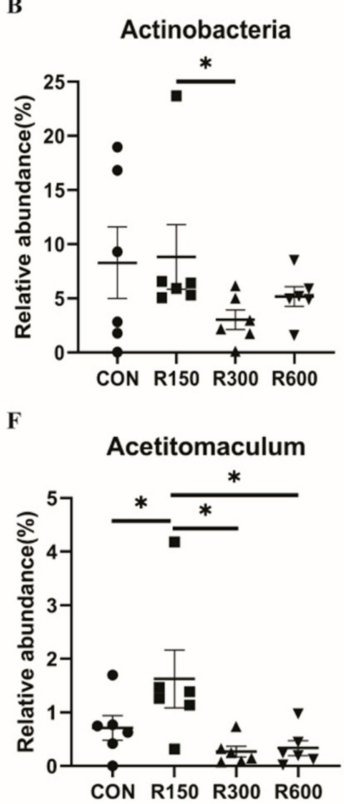

C

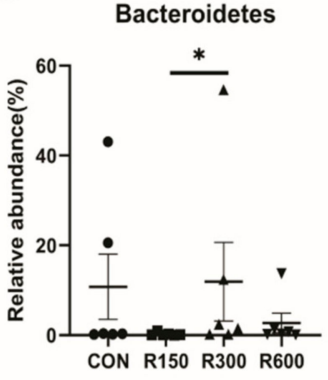

G

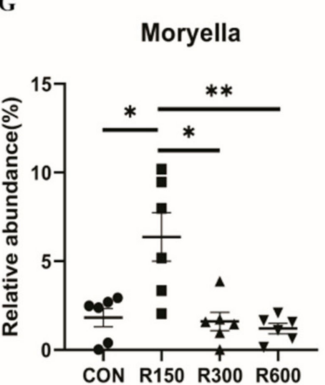

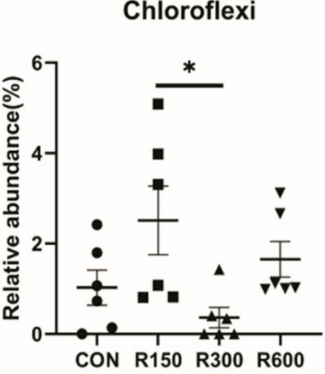

H

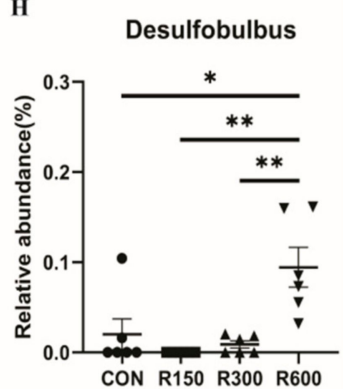

Figure 3. Ruminal microbiota at the phylum (A-E) and genus (F-H) level affected by dietary resveratrol supplementation in fattening goats. All values are expressed as means $\pm \mathrm{SEM}, n=6 .{ }^{*}$ or ** represent a significant or extremely significant difference between the two groups at two terminals of the bar appearing below these characters. ${ }^{*} p<0.05,{ }^{* *} p<0.01$. CON, the control group; R150, the $150 \mathrm{mg} / \mathrm{kg}$ RES group; R300, the $300 \mathrm{mg} / \mathrm{kg}$ RES group; R600, the $600 \mathrm{mg} / \mathrm{kg}$ RES group.

Significant differences in microbial species between the four groups of finishing goats were identified following LEfSe analysis (LDA = 3). Specifically, the LEfSe analysis revealed that 
six genera were potential biomarkers to distinguish different treatment groups (Figure 4), with one genus exclusive to the control group, four genera endemic to the $150 \mathrm{mg} / \mathrm{kg}$ RES group and one genus unique to the $600 \mathrm{mg} / \mathrm{kg}$ RES group. The control group was characterized by $g \_D N F 00809$ and $s \_u n c u l t u r e d \_b a c t e r i u m \_g \_D N F 00809(p<0.05)$. The results revealed that levels of the following were significantly enriched in the $150 \mathrm{mg} / \mathrm{kg}$ RES group: $p$ _Chloroflexi, c_Anaerolineae, o_Anaerolineales, $f \_$Anaerolineaceae, g_Flexilinea, s_uncultured_bacterium_g_Flexilinea, g_uncultured_bacterium_f_Atopobiaceae,s_uncultured_bacterium_f_Atopobiaceae, s_uncultured_bacterium ___Atopobium, g_Acetitomaculum, s_uncultured_bacterium_g_Acetitomaculum, g_Moryella and s_uncultured_bacterium_g_Moryella. The $600 \mathrm{mg} / \mathrm{kg}$ RES group, on the other hand, was marked by c_Deltaproteobacteria, o_Desulfobacterales, $f \_$Desulfobulbaceae, $g$ _Desulfobulbus and s_uncultured _bacterium_g_Desulfobulbus. There were no biomarkers with statistical differences in the $300 \mathrm{mg} / \mathrm{kg}$ RES group. These results indicate that different supplemental levels of RES could lead to characteristic differences in ruminal bacterial taxa.

A

Cladogram
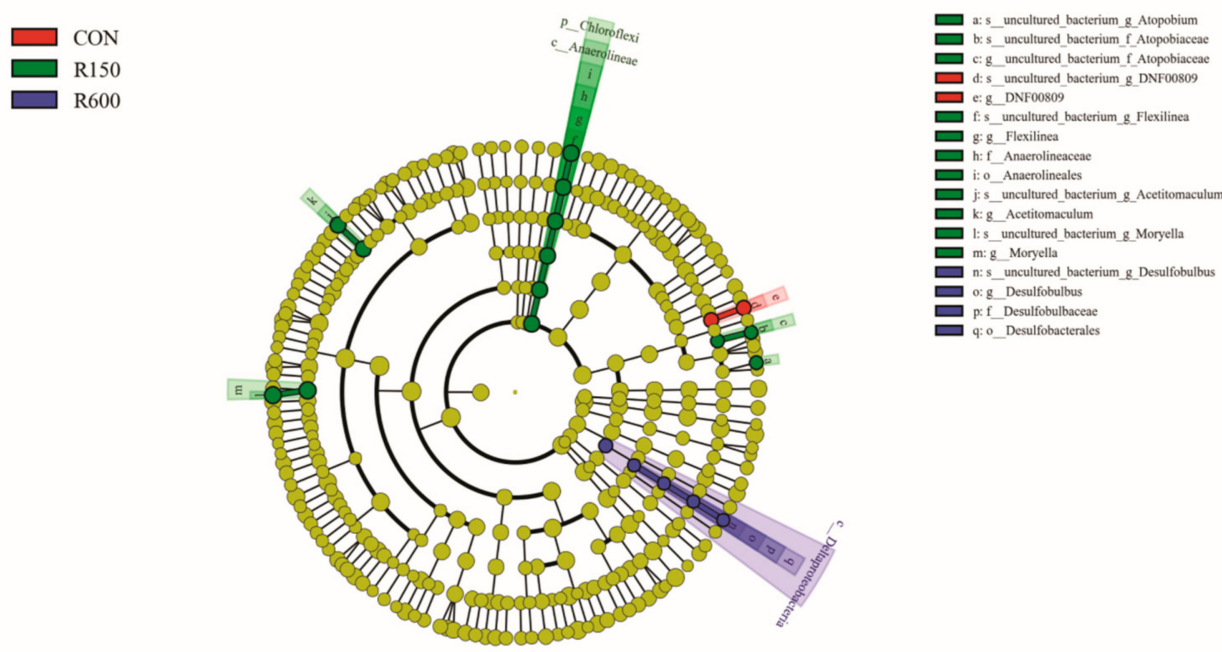

B

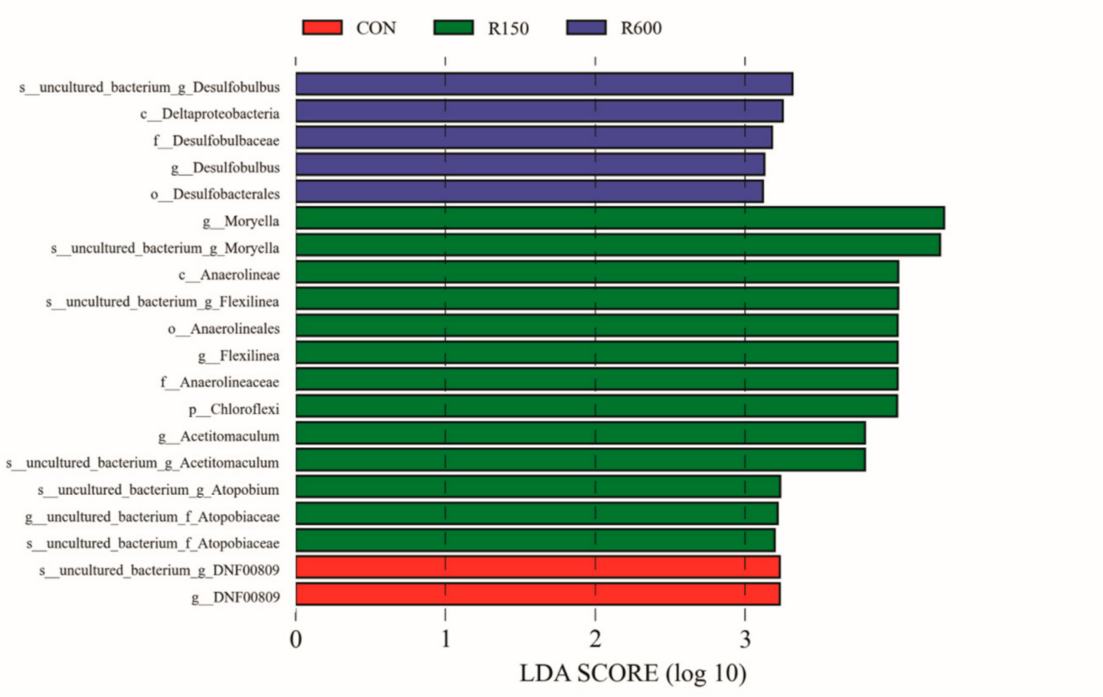

Figure 4. The LDA effect size (LEfSe) analysis of ruminal bacterial taxa affected by dietary resveratrol supplementation in fattening goats. (A) Cladogram displays significantly enriched bacterial taxa (from the class to the species level). (B) Bar chart displays LDA scores for different treatments. Different colors represent particular bacterial taxa that were enriched in the different groups. Significant differences are defined as $p<0.05$ and LDA score $>3.0$. There were no biomarkers with statistical differences in the $300 \mathrm{mg} / \mathrm{kg}$ RES group. CON, the control group; R150, the $150 \mathrm{mg} / \mathrm{kg}$ RES group; $\mathrm{R} 300$, the $300 \mathrm{mg} / \mathrm{kg}$ RES group; R600, the $600 \mathrm{mg} / \mathrm{kg}$ RES group. 


\subsubsection{Functional Prediction of Rumen Microbiota among Different Treatments}

Alterations in the supposed function of the ruminal microbiota in fattening goats due to dietary RES supplementation were evaluated using the PICRUSt2 software. The KEGG Ontology (KO) abundances were mainly affected by the global and overview maps, carbohydrate metabolism and amino acid metabolism across the different groups (Figure 5A). Metabolism pathways of cofactors and vitamins were detected at significantly higher levels in the microbiota of the $600 \mathrm{mg} / \mathrm{kg}$ RES group versus the $150 \mathrm{mg} / \mathrm{kg}$ RES group $(p<0.05$; Figure $5 \mathrm{~B}$ ), with no other significant difference in $\mathrm{KO}$ abundances in annotation pathways across the treatments ( $p>0.05$; Table S5).

A

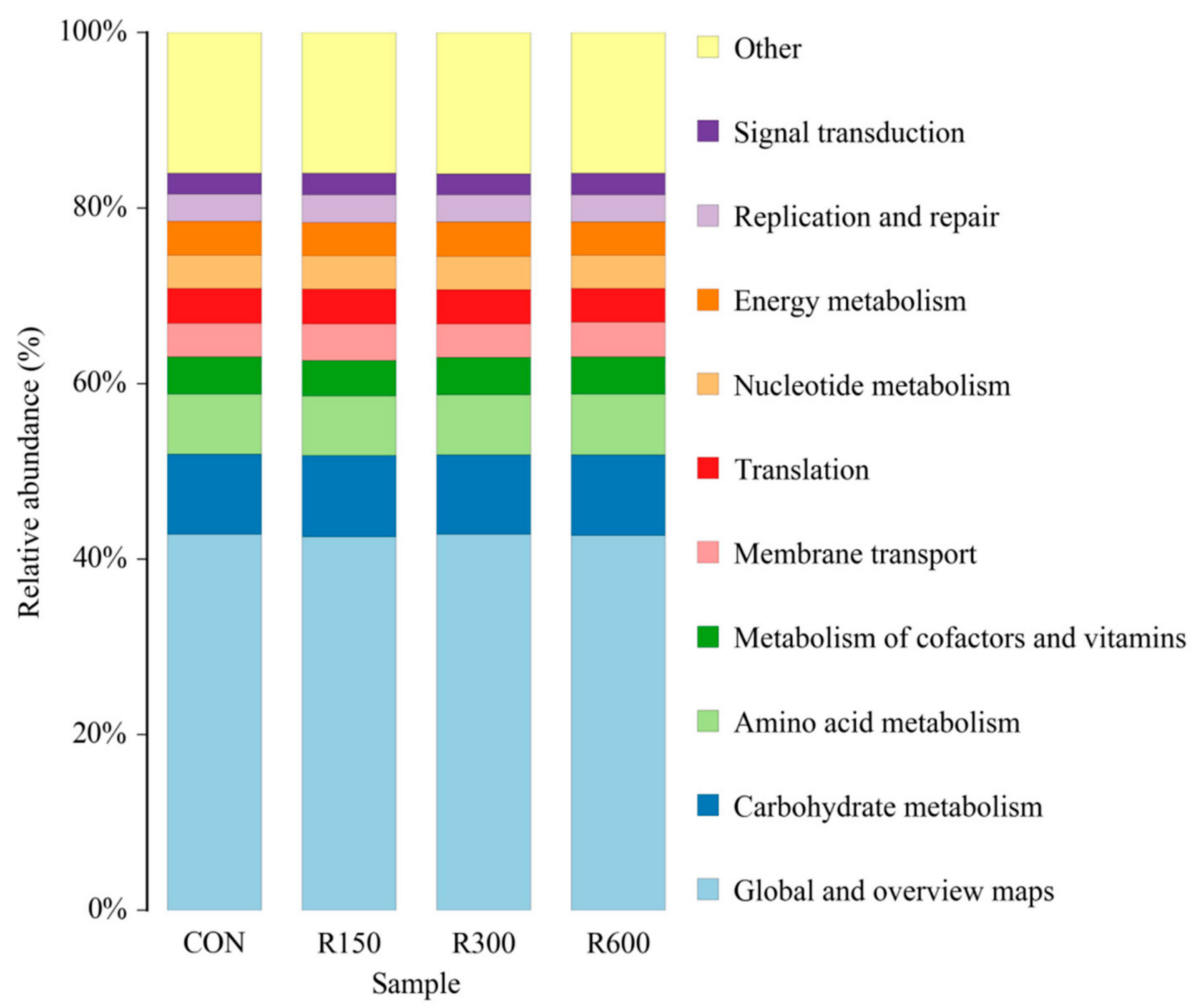

B
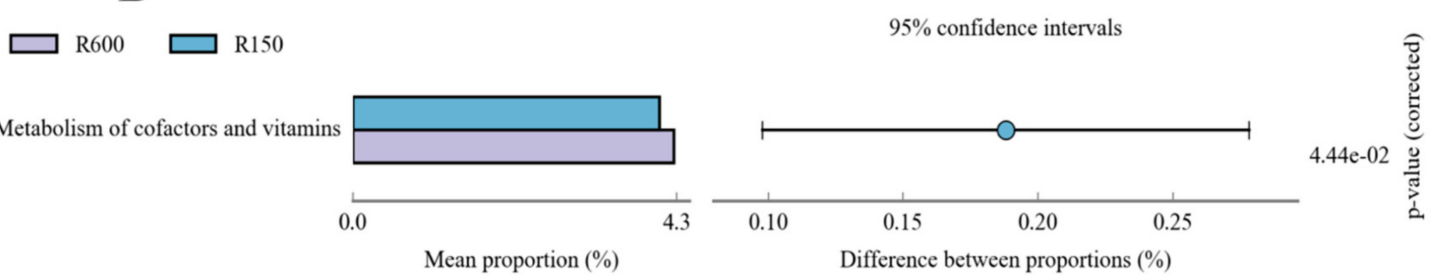

Figure 5. The different functions of the ruminal microbiota affected by dietary resveratrol supplementation in fattening goats. The top ten KEGG pathways (A) and the significant different functions (B) were predicted using PICRUSt2 software at level 2 across treatments. CON, the control group; R150, the $150 \mathrm{mg} / \mathrm{kg}$ RES group; R300, the $300 \mathrm{mg} / \mathrm{kg}$ RES group; R600, the $600 \mathrm{mg} / \mathrm{kg}$ RES group.

\section{Discussion}

In order to investigate the effect of RES on fattening goats, we fed goats with different levels of RES (0, 150, 300 and $600 \mathrm{mg} / \mathrm{kg})$ and studied the differences in growth performance, meat quality and rumen microbiota sequenced using full-length 16S rRNA sequencing. To our knowledge, this is the first research to report that adding different 
levels of RES could affect growth and rumen microbiota, as well as improving meat quality and plasma lipid metabolism in fattening goats.

Some studies have shown that dietary RES supplementation had no significant effect on the growth performance and carcass characteristics of finishing pigs [6,21]. However, Meng et al. (2019) found that dietary RES in sows could increase the average daily weight gains of piglets [9]. Likewise, dietary supplementation with $400 \mathrm{mg} / \mathrm{kg}$ RES improved the FCR and final body weight of broilers subjected to transport stress [7]. In this study, we observed that different supplemental levels of RES had different effects on the growth performance and carcass characteristics of goats. Treatment with $300 \mathrm{mg} / \mathrm{kg}$ RES for $120 \mathrm{~d}$ had no significant effect on food intake, body weight or carcass characteristics, which is consistent with some previous studies in mice and pigs [5,6,21]. Dietary RES supplementation has previously been found to have no significant effects on carcass characteristics including carcass weight, dressing percentage and LD muscle area in finishing pigs $[6,21]$. Consistent with this, our study found that supplementation with $300 \mathrm{mg} / \mathrm{kg}$ RES had no significant effect on these carcass traits in fattening goats. However, we also found that supplementation with $150 \mathrm{mg} / \mathrm{kg}$ RES did significantly increase the average daily gain and carcass lean percentage of goats, while dietary supplementation with $600 \mathrm{mg} / \mathrm{kg}$ RES had the opposite effect. The lowest daily feed intake was observed in the $600 \mathrm{mg} / \mathrm{kg}$ RES group compared with the other groups, which was probably the reason for the significantly slower growth rate in the $600 \mathrm{mg} / \mathrm{kg}$ RES group. Although so far no research has reported adverse effects of RES on feed intake and growth rate, one study found that eugenol (another phenol) administered at a high level $(1600 \mathrm{mg} / \mathrm{d})$ had negative effects on fattening beef cattle [22]. High concentrations of some phenols inhibit rumen microbial growth and rumen fermentation, which are crucial for nutrient transformation in muscle tissue [23-25], but whether the mechanism of RES is consistent with these findings is a topic that requires further study.

Meat color is one of the most important meat quality indicators determining consumer acceptance and purchase decisions, and is related to myoglobin content, especially the $\mathrm{a}^{*}$ value. Our results indicate that the $\mathrm{a}^{*}$ value of the LD muscle increases with an increase in the RES supplementation level. These results were consistent with other studies on pigs [6], chickens [8] and ducks [26]. It has been reported that RES has antioxidant properties that protect mitochondrial function in muscles, prevent free radical attacks and reduce myoglobin oxidation, thus improving the color of meat $[27,28]$. Therefore, the increase in the $a^{*}$ value of the meat samples may be related to the effect of RES on antioxidant performance. IMF content is a significant index affecting meat quality, essential for the juiciness, tenderness and flavor of meat $[29,30]$. In this study, the IMF contents of the LD muscle were significantly increased by RES supplementation in growing-fattening goats, which is in line with findings from other studies in pigs [21] and ducks [26]. Another previous study has reported that dietary RES supplementation could significantly improve the IMF content in growing-finishing pigs, which might be connected with the promotion of intramuscular lipid anabolism and repression of intramuscular lipid catabolism [21]. The mechanism by which RES improves intramuscular fat content in fattening goats requires further study. Shear force plays an important role in the evaluation of meat tenderness, and is also one of the conventional indicators used in meat quality evaluation [31]. In this study, dietary RES supplementation significantly reduced the shear force of the LD muscle, a finding in line with a previous report on growing-finishing pigs [6]. These results reveal that dietary RES supplementation improved some meat quality indexes ( $a^{*}$ value, IMF content and shear force) in the LD muscle of goats.

Elevated levels of total cholesterol, LDL cholesterol and triglycerides and decreased levels of HDL cholesterol in the blood are characteristic of dyslipidemia and are associated with an increased risk of cardiovascular disease [32-34]. Previous reports on animals and humans have indicated that RES decreased levels of triacylglycerol and LDL-C and increased the levels of HDL-C in the blood [15,32,35-37]. In this study, serum triacylglycerol and LDL-C levels in the RES groups were significantly decreased versus the control group. 
A higher HDL-C level and HDL-C/TC ratio were observed in the RES groups, consistent with the results reported by other authors [37]. HDL-C is widely referred to as good cholesterol, because it transports cholesterol currently present in body tissues and blood vessels to the liver for processing, thereby reducing the risk of developing atherosclerotic diseases, such as heart attacks and strokes [38,39]. Our results demonstrated that RES could greatly improve blood lipid profiles in fattening goats. The blood physiological indexes showed that RES had no obvious effect on the health of goats, which was consistent with the study reported by Huang et al. (2020) [5].

Up to now, the research on RES in ruminants has mainly focused on its impact on methane emissions and rumen fermentation [18,19]. Wang et al. (2020) found that RES mitigated methane production in in vitro fermentation techniques, which may be related to a decreased abundance of Methanobrevibacter [19]. In addition, it has been reported that dietary RES supplementation increased the proportion of Fibrobacter succinogenes, $R u$ minococcus albus and Butyrivibrio fibrisolvens $(p<0.001)$ while decreasing the abundance of protozoa and methanogens in the rumen fluid of sheep [18]. In this study, the ruminal microbiota was analyzed via full-length $16 \mathrm{~S}$ rRNA gene sequencing. The results of this phase of the experiment showed that although there were no apparent differences in microbiota diversity values across the treatments, differences in ruminal microbiota abundance were observed at the phylum, genus and species level. The $150 \mathrm{mg} / \mathrm{kg}$ RES group exhibited a significant increase in the relative abundances of Acetitomaculum and Moryella compared with the other three groups in this study. The genus Acetitomaculum is a short-chain fatty acid-producing bacteria [40]. In addition, Acetitomaculum and Moryella both belong to the family Lachnospiraceae, members of which are known for their ability to synthesize short-chain fatty acids (SCFAs) through the fermentation of dietary polysaccharides [41-44], and SCFAs in turn are an important substrate for maintaining gastrointestinal epithelium and regulating the immune system and inflammatory response [45]. Consistent with these findings, Meng et al. (2019) reported that maternal dietary resveratrol increased the relative abundance of butyrate-producing bacteria in weaning piglets, and, moreover, that dietary supplementation with $600 \mathrm{mg} / \mathrm{kg}$ RES increased the relative abundance of Deltaproteobacteria, including Desulfobulbus [9]. The class Deltaproteobacteria is the main representative of sulfate-reducing bacteria, which can counter the accumulation of toxic hydrogen sulfide gas, produced when ruminants consume large amounts of sulfate [46,47]. Elsewhere, it has been reported that hydrogen sulfide can inhibit the production of SCFAs, in particular preventing the oxidation of butyrate, therefore affecting energy acquisition, weight gain and feed efficiency [48]. The results of the present research showed that dietary RES supplementation could affect the composition of rumen microbiota in goats, and that these effects differ depending on the level of RES supplementation.

\section{Conclusions}

In this study, we found that an appropriate supplementation of RES $(150 \mathrm{mg} / \mathrm{kg})$ can ameliorate growth performance and carcass traits, improve meat quality and blood lipid metabolism levels and alter the composition of rumen microbiota in fattening goats. However, feeding high doses of RES $(600 \mathrm{mg} / \mathrm{kg})$ reduced the growth rate and meat yield of goats. Moderate use of RES can improve the production performance of fattening goats, and has potential to be developed into a goat feed additive.

Supplementary Materials: The following supporting information can be downloaded at: https: / / www.mdpi.com/article/10.3390/foods11040598/s1, Figure S1. Rarefaction curves on the OTU numbers of all the rumen fluid samples in fattening goats. $X$-axis represents the number of sequences picked randomly; Y-axis represents the OTU number based on the clustering of these sequences; individual curves represent each sample and are marked by different colors. The control group (CON) includes six samples: CON1-6; the $150 \mathrm{mg} / \mathrm{kg}$ RES group (R150) include six samples: RES7-RES12; the $300 \mathrm{mg} / \mathrm{kg}$ RES group (R300) include six samples: RES7-RES12; and the $600 \mathrm{mg} / \mathrm{kg}$ RES group (R600) include six samples: RES13-RES18. Figure S2. Relative abundances of genera(A) and species (B) in the rumen fluid samples of fattening goats are presented as heatmaps. CON, the control group; 
R150, the $150 \mathrm{mg} / \mathrm{kg}$ RES group; R300, the $300 \mathrm{mg} / \mathrm{kg}$ RES group; R600, the $600 \mathrm{mg} / \mathrm{kg}$ RES group. Table S1. Effect of dietary resveratrol supplementation on blood physiological index of goats. Table S2. Summary of the full-length 16S rRNA sequencing data of rumen fluid samples in fattening goats. Table S3. The 23 bacterial genera significantly affected by dietary resveratrol supplementation in fattening goats. Table S4. The 26 bacterial species significantly affected by dietary resveratrol supplementation in fattening goats. Table S5. Comparison of the appointed KEGG pathways across treatments using t-test based on PICRUSt2 software.

Author Contributions: Project administration, supervision and writing-review and editing, Q.J. and Y.H. (Yanna Huang); investigation and writing-original draft preparation, Y.S. (Yujian Shen) and Y.J.; methodology, S.Z.; conceptualization, J.Z.; software, X.G.; validation, Y.S. (Ying Song); data curation, Y.Z. and Y.H. (Yan Hu) All authors have read and agreed to the published version of the manuscript.

Funding: This study was supported by the National Key R\&D Program of China (2021YFD1100104 and 2021YFD1100105), the Guangxi innovation team of cattle and goat industry (nycytxgxcxtd-202109) and the Innovation Project of Guangxi Graduate Education (YCBZ2020028).

Institutional Review Board Statement: The animal study protocol was approved by the Animal Care and Welfare Committee of Guangxi University (GXU2020-041, 2020-04-06).

Informed Consent Statement: Not applicable.

Data Availability Statement: The data presented in this study are available upon request from authors.

Conflicts of Interest: The authors declare no conflict of interest.

\section{References}

1. Ko, J.-H.; Sethi, G.; Um, J.-Y.; Shanmugam, M.K.; Arfuso, F.; Kumar, A.P.; Bishayee, A.; Ahn, K.S. The Role of Resveratrol in Cancer Therapy. Int. J. Mol. Sci. 2017, 18, 2589. [CrossRef]

2. Liu, L.L.; He, J.H.; Xie, H.B.; Yang, Y.S.; Li, J.C.; Zou, Y. Resveratrol induces antioxidant and heat shock protein mRNA expression in response to heat stress in black-boned chickens. Poult. Sci. 2014, 93, 54-62. [CrossRef] [PubMed]

3. Donnelly, L.E.; Newton, R.; Kennedy, G.E.; Fenwick, P.S.; Leung, R.H.F.; Ito, K.; Russell, R.E.K.; Barnes, P.J. Anti-inflammatory effects of resveratrol in lung epithelial cells: Molecular mechanisms. Am. J. Physiol. Cell. Mol. Physiol. 2004, 287, L774-L783. [CrossRef]

4. Xing, T.; Xu, X.L.; Zhou, G.H.; Wang, P.; Jiang, N.N. The effect of transportation of broilers during summer on the expression of heat shock protein 70, postmortem metabolism and meat quality. J. Anim. Sci. 2015, 93, 62-70. [CrossRef] [PubMed]

5. Huang, Y.; Xia, Q.; Cui, Y.; Qu, Q.; Wei, Y.; Jiang, Q. Resveratrol increase the proportion of oxidative muscle fiber through the AdipoR1-AMPK-PGC-1 $\alpha$ pathway in pigs. J. Funct. Foods 2020, 73, 104090. [CrossRef]

6. Zhang, C.; Luo, J.; Yu, B.; Zheng, P.; Huang, Z.; Mao, X.; He, J.; Yu, J.; Chen, J.; Chen, D. Dietary resveratrol supplementation improves meat quality of finishing pigs through changing muscle fiber characteristics and antioxidative status. Meat Sci. 2015, 102, 15-21. [CrossRef] [PubMed]

7. Zhang, C.; Wang, L.; Zhao, X.H.; Chen, X.Y.; Yang, L.; Geng, Z.Y. Dietary resveratrol supplementation prevents transport-stressimpaired meat quality of broilers through maintaining muscle energy metabolism and antioxidant status. Poult. Sci. 2017, 96, 2219-2225. [CrossRef] [PubMed]

8. Zhang, C.; Zhao, X.; Wang, L.; Yang, L.; Chen, X.; Geng, Z. Resveratrol beneficially affects meat quality of heat-stressed broilers which is associated with changes in muscle antioxidant status. Anim. Sci. J. 2017, 88, 1569-1574. [CrossRef]

9. Meng, Q.; Sun, S.; Luo, Z.; Shi, B.; Shan, A.; Cheng, B. Maternal dietary resveratrol alleviates weaning-associated diarrhea and intestinal inflammation in pig offspring by changing intestinal gene expression and microbiota. Food Funct. 2019, 10, 5626-5643. [CrossRef]

10. Jeon, Y.O.; Lee, J.-S.; Lee, H.G. Improving solubility, stability, and cellular uptake of resveratrol by nanoencapsulation with chitosan and $\gamma$-poly (glutamic acid). Colloids Surf. B Biointerfaces 2016, 147, 224-233. [CrossRef]

11. Yin, X.; Liao, W.; Li, Q.; Zhang, H.; Liu, Z.; Zheng, X.; Zheng, L.; Feng, X. Interactions between resveratrol and gut microbiota affect the development of hepatic steatosis: A fecal microbiota transplantation study in high-fat diet mice. J. Funct. Foods 2020, 67, 103883. [CrossRef]

12. Zhao, Y.N.; Cao, Y.N.; Sun, J.; Liang, Z.; Wu, Q.; Cui, S.H.; Zhi, D.F.; Guo, S.T.; Zhen, Y.H.; Zhang, S.B. Anti-breast cancer activity of resveratrol encapsulated in liposomes. J. Mater. Chem. B 2020, 8, 27-37. [CrossRef] [PubMed]

13. Azorín-Ortuño, M.; Yáñez-Gascón, M.J.; Vallejo, F.; Pallarés, F.J.; Larrosa, M.; Lucas, R.; Morales, J.C.; Tomás-Barberán, F.A.; García-Conesa, M.T.; Espín, J.C. Metabolites and tissue distribution of resveratrol in the pig. Mol. Nutr. Food Res. 2011, 55, 1154-1168. [CrossRef] [PubMed] 
14. Larrosa, M.; Yañéz-Gascón, M.J.; Selma, M.V.; González-Sarrías, A.; Toti, S.; Ceron, J.; Tomas-Barberan, F.; Dolara, P.; Espín, J.C. Effect of a Low Dose of Dietary Resveratrol on Colon Microbiota, Inflammation and Tissue Damage in a DSS-Induced Colitis Rat Model. J. Agric. Food Chem. 2009, 57, 2211-2220. [CrossRef]

15. Qiao, Y.; Sun, J.; Xia, S.; Tang, X.; Shi, Y.; Luo, T. Effects of resveratrol on gut microbiota and fat storage in a mouse model with high-fat-induced obesity. Food Funct. 2014, 5, 1241-1249. [CrossRef]

16. McGovern, E.; Kenny, D.A.; McCabe, M.S.; Fitzsimons, C.; McGee, M.; Kelly, A.K.; Waters, S.M. 16S rRNA Sequencing Reveals Relationship Between Potent Cellulolytic Genera and Feed Efficiency in the Rumen of Bulls. Front. Microbiol. 2018, 9 , 1842. [CrossRef]

17. Lin, L.; Xie, F.; Sun, D.; Liu, J.; Zhu, W.; Mao, S. Ruminal microbiome-host crosstalk stimulates the development of the ruminal epithelium in a lamb model. Microbiome 2019, 7, 83. [CrossRef]

18. Ma, T.; Chen, D.-D.; Tu, Y.; Zhang, N.-F.; Si, B.-W.; Deng, K.-D.; Diao, Q.-Y. Effect of dietary supplementation with resveratrol on nutrient digestibility, methanogenesis and ruminal microbial flora in sheep. J. Anim. Physiol. Anim. Nutr. 2014, 99, 676-683. [CrossRef]

19. Ma, T.; Wu, W.; Tu, Y.; Zhang, N.; Diao, Q. Resveratrol affects in vitro rumen fermentation, methane production and prokaryotic community composition in a time- and diet-specific manner. Microb. Biotechnol. 2020, 13, 1118-1131. [CrossRef]

20. Lee, M. Official and standardized methods of analysis (3rd edn): Edited by C.A. Watson, Royal Society of Chemistry, 1994 . $£ 110.00$ (xxiv + 778 pages) ISBN 085186441 4. Trends Food Sci. Technol. 1995, 6, 382-383. [CrossRef]

21. Zhang, H.Z.; Chen, D.W.; He, J.; Zheng, P.; Yu, J.; Mao, X.B.; Huang, Z.Q.; Luo, Y.H.; Luo, J.Q.; Yu, B. Long-term dietary resveratrol supplementation decreased serum lipids levels, improved intramuscular fat content, and changed the expression of several lipid metabolism-related miRNAs and genes in growing-finishing pigs1. J. Anim. Sci. 2019, 97, 1745-1756. [CrossRef] [PubMed]

22. Yang, W.; Benchaar, C.; Ametaj, B.; Beauchemin, K. Dose response to eugenol supplementation in growing beef cattle: Ruminal fermentation and intestinal digestion. Anim. Feed Sci. Technol. 2010, 158, 57-64. [CrossRef]

23. Santra, A.; Karim, S.A. Rumen Manipulation to Improve Animal Productivity. Asian-Australas. J. Anim. Sci. 2003, 16, 748-763. [CrossRef]

24. Valenzuela-Grijalva, N.V.; Pinelli-Saavedra, A.; Muhlia-Almazan, A.; Domínguez-Díaz, D.; González-Ríos, H. Dietary inclusion effects of phytochemicals as growth promoters in animal production. J. Anim. Sci. Technol. 2017, 59, 8. [CrossRef] [PubMed]

25. Wanapat, M.; Kang, S.; Polyorach, S. Development of feeding systems and strategies of supplementation to enhance rumen fermentation and ruminant production in the tropics. J. Anim. Sci. Biotechnol. 2013, 4, 32. [CrossRef] [PubMed]

26. Yu, Q.; Fang, C.; Ma, Y.; He, S.; Ajuwon, K.M.; He, J. Dietary resveratrol supplement improves carcass traits and meat quality of Pekin ducks. Poult. Sci. 2021, 100, 100802. [CrossRef] [PubMed]

27. Griñán-Ferré, C.; Bellver-Sanchis, A.; Izquierdo, V.; Corpas, R.; Roig-Soriano, J.; Chillón, M.; Andres-Lacueva, C.; Somogyvári, M.; Sőti, C.; Sanfeliu, C.; et al. The pleiotropic neuroprotective effects of resveratrol in cognitive decline and Alzheimer's disease pathology: From antioxidant to epigenetic therapy. Ageing Res. Rev. 2021, 67, 101271. [CrossRef]

28. Musial, C.; Siedlecka-Kroplewska, K.; Kmiec, Z.; Gorska-Ponikowska, M. Modulation of Autophagy in Cancer Cells by Dietary Polyphenols. Antioxidants 2021, 10, 123. [CrossRef]

29. Chartrin, P.; Méteau, K.; Juin, H.; Bernadet, M.D.; Guy, G.; Larzul, C.; Rémignon, H.; Mourot, J.; Duclos, M.; Baéza, E. Effects of Intramuscular Fat Levels on Sensory Characteristics of Duck Breast Meat. Poult. Sci. 2006, 85, 914-922. [CrossRef]

30. Zhao, J.X.; Li, Q.; Zhang, R.X.; Liu, W.Z.; Ren, Y.S.; Zhang, C.X.; Zhang, J.X. Effect of dietary grape pomace on growth performance, meat quality and antioxidant activity in ram lambs. Anim. Feed Sci. Technol. 2018, 236, 76-85. [CrossRef]

31. Huff-Lonergan, E.; Baas, T.J.; Malek, M.; Dekkers, J.C.M.; Prusa, K.; Rothschild, M.F. Correlations among selected pork quality traits. J. Anim. Sci. 2002, 80, 617-627. [CrossRef] [PubMed]

32. Hoseini, A.; Namazi, G.; Farrokhian, A.; Reiner, Ž.; Aghadavod, E.; Bahmani, F.; Asemi, Z. The effects of resveratrol on metabolic status in patients with type 2 diabetes mellitus and coronary heart disease. Food Funct. 2019, 10, 6042-6051. [CrossRef] [PubMed]

33. Hunter, P.M.; Hegele, R.A. Functional foods and dietary supplements for the management of dyslipidaemia. Nat. Rev. Endocrinol. 2017, 13, 278-288. [CrossRef] [PubMed]

34. Jin, D.; Xu, Y.; Mei, X.; Meng, Q.; Gao, Y.; Li, B.; Tu, Y. Antiobesity and lipid lowering effects of theaflavins on high-fat diet induced obese rats. J. Funct. Foods 2013, 5, 1142-1150. [CrossRef]

35. Guo, X.-F.; Li, J.-M.; Tang, J.; Li, D. Effects of resveratrol supplementation on risk factors of non-communicable diseases: A meta-analysis of randomized controlled trials. Crit. Rev. Food Sci. Nutr. 2018, 58, 3016-3029. [CrossRef] [PubMed]

36. Wang, B.; Sun, J.; Li, L.; Zheng, J.; Shi, Y.; Le, G. Regulatory effects of resveratrol on glucose metabolism and T-lymphocyte subsets in the development of high-fat diet-induced obesity in C57BL/ 6 mice. Food Funct. 2014, 5, 1452-1463. [CrossRef]

37. Zhang, C.; Luo, J.; Yu, B.; Chen, J.; Chen, D. Effects of resveratrol on lipid metabolism in muscle and adipose tissues: A reevaluation in a pig model. J. Funct. Foods 2015, 14, 590-595. [CrossRef]

38. Kutbi, E.H.; Sohouli, M.H.; Fatahi, S.; Lari, A.; Shidfar, F.; Aljhdali, M.M.; Alhoshan, F.M.; Elahi, S.S.; Almusa, H.A.; Abu-Zaid, A. The beneficial effects of cinnamon among patients with metabolic diseases: A systematic review and dose-response meta-analysis of randomized-controlled trials. Crit. Rev. Food Sci. Nutr. 2021, 4, 1-19. [CrossRef]

39. Le Lay, J.E.; Du, Q.; Mehta, M.B.; Bhagroo, N.; Hummer, B.T.; Falloon, J.; Carlson, G.; Rosenbaum, A.I.; Jin, C.; Kimko, H.; et al. Blocking endothelial lipase with monoclonal antibody MEDI5884 durably increases high density lipoprotein in nonhuman primates and in a phase 1 trial. Sci. Transl. Med. 2021, 13, eabb0602. [CrossRef] 
40. Lin, L.; Trabi, E.B.; Xie, F.; Mao, S. Comparison of the fermentation and bacterial community in the colon of Hu sheep fed a low-grain, non-pelleted, or pelleted high-grain diet. Appl. Microbiol. Biotechnol. 2021, 105, 2071-2080. [CrossRef]

41. Barichella, M.; Severgnini, M.; Cilia, R.; Cassani, E.; Bolliri, C.; Caronni, S.; Ferri, V.; Cancello, R.; Ceccarani, C.; Faierman, S.; et al. Unraveling gut microbiota in Parkinson's disease and atypical parkinsonism. Mov. Disord. 2019, 34, 396-405. [CrossRef] [PubMed]

42. Laffin, M.; Fedorak, R.; Zalasky, A.; Park, H.; Gill, A.; Agrawal, A.; Keshteli, A.; Hotte, N.; Madsen, K.L. A high-sugar diet rapidly enhances susceptibility to colitis via depletion of luminal short-chain fatty acids in mice. Sci. Rep. 2019, 9, 12294. [CrossRef] [PubMed]

43. Truax, A.D.; Chen, L.; Tam, J.W.; Cheng, N.; Guo, H.; Koblansky, A.A.; Chou, W.-C.; Wilson, J.E.; Brickey, W.J.; Petrucelli, A.; et al. The Inhibitory Innate Immune Sensor NLRP12 Maintains a Threshold against Obesity by Regulating Gut Microbiota Homeostasis. Cell Host Microbe 2018, 24, 364-378.e6. [CrossRef] [PubMed]

44. Vascellari, S.; Palmas, V.; Melis, M.; Pisanu, S.; Cusano, R.; Uva, P.; Perra, D.; Madau, V.; Sarchioto, M.; Oppo, V.; et al. Gut Microbiota and Metabolome Alterations Associated with Parkinson's Disease. mSystems 2020, 5, e00561-e00520. [CrossRef] [PubMed]

45. Guo, H.; Chou, W.-C.; Lai, Y.; Liang, K.; Tam, J.W.; Brickey, W.J.; Chen, L.; Montgomery, N.D.; Li, X.; Bohannon, L.M.; et al. Multi-omics analyses of radiation survivors identify radioprotective microbes and metabolites. Science 2020, 370 , eaay9097. [CrossRef]

46. Anderson, C.J.; Koester, L.R.; Schmitz-Esser, S. Rumen Epithelial Communities Share a Core Bacterial Microbiota: A Meta-Analysis of $16 \mathrm{~S}$ rRNA Gene Illumina MiSeq Sequencing Datasets. Front. Microbiol. 2021, 12, 625400. [CrossRef]

47. Fernández-Calleja, J.; Konstanti, P.; Swarts, H.J.M.; Bouwman, L.; Garcia-Campayo, V.; Billecke, N.; Oosting, A.; Smidt, H.; Keijer J.; Van Schothorst, E.M. Non-invasive continuous real-time in vivo analysis of microbial hydrogen production shows adaptation to fermentable carbohydrates in mice. Sci. Rep. 2018, 8, 15351. [CrossRef]

48. Zhang, Y.; Zhang, X.; Li, F.; Li, C.; Li, G.; Zhang, D.; Song, Q.; Li, X.; Zhao, Y.; Wang, W. Characterization of the rumen microbiota and its relationship with residual feed intake in sheep. Animal 2021, 15, 100161. [CrossRef] 